\title{
Comment
}

Neuroepidemiology 2010;35:280

DOI: $10.1159 / 000320844$

\section{Is Carotid Atherosclerosis Epidemiology Changed among Egyptians?}

\section{Nicola Cicorella}

Department of Cardiovascular and Thoracic Disease, Carlo Poma Hospital, Mantova, Italy

In recent times, the health profile in the developing world has changed [1] and there are no accurate national estimates of the prevalence of atherosclerosis diseases. Cardiovascular diseases are now the main cause of death among Egyptians: in 1970 they accounted for $12.4 \%$ of all deaths, whereas 2 decades later they were responsible for $42.5 \%$ of the mortality [2].

The study by Abd Allah et al. [3] gives new and interesting information about carotid atherosclerosis epidemiology among a large cohort of 4,733 patients in Cairo who underwent extracranial carotid duplex scanning during a 5-year follow-up. This study enrolled a wide and unselected population of patients, as you can find in a common division of neurology, with the important advantage of generalizability. The authors found that atherosclerotic carotid artery disease (intima-media thickness and/or plaques) was present in $41 \%$ of the study population, but significant and clinically relevant stenosis was detected in only $2.5 \%$ of the symptomatic subjects. This study confirms that age, diabetes mellitus, hypertension, smoking and dyslipidemia are independent predictors of carotid atherosclerotic disease.

Hemodynamically significant and clinically relevant extracranial atherosclerotic carotid disease is rare among Egyptians. This finding is in contrast with study results by Bishara et al. [4], which show that the prevalence of carotid artery disease in their cohort of 1,000 Egyptian patients was similar to that in matched patients of Western populations, and that significant stenosis was detected in $16 \%$ of symptomatic subjects.

It would be interesting to use carotid Doppler to differentiate the types of plaque: it is known, in fact, that hypoechogenic and/ or echolucent (unstable) plaques are associated with a high risk of cardiovascular events [5]. Abd Allah et al. [3] suspect that lifestyle and the nutrition of Cairenes are major contributors to the lower prevalence of carotid disease in Egyptians. Many residents have moved only recently from farming lands to Cairo, and few are overweight. However, their lifestyle has undergone important changes with the introduction of industrialization, increased urbanization and internal immigration to cities, changes in dietary habits, obesity, less physical activity and increased psychosocial stress $[1,6]$. These factors are going to change the epidemiological profile, and cases of atherosclerosis among the next generations of Egyptians might be increasing in number [7].

Furthermore, several studies have reported racial differences in the severity and distribution of carotid atherosclerosis $[8,9]$, e.g. people of South Asian origin have higher rates of cardiovascular disease and stroke than people of European origin, a finding that cannot be explained entirely by differences in conventional cardiovascular risk factors such as smoking, elevated blood pressure, diabetes or raised serum cholesterol.

These considerations confirm the importance of duplex ultrasound examination: it is accurate, reproducible and not expensive, and capable of diagnosing and following patients with arterial disorders. Furthermore, carotid Doppler can be used to estimate cardiovascular risk profiles [10]; the finding of carotid plaques might be considered a surrogate for early coronary atherosclerosis [11], but further research is still needed to better validate these observations. Actually, in spite of the attention given to cardiovascular prevention, the low-cost, easy and noninvasive carotid ultrasonographic evaluation is not widely known or used [12]. The findings of this study should move authorities to conduct national preventive programs and health education in order to promote a healthier society.

\section{References}

1 Ibrahim MM: Hypertension surveys in the developing world: lessons from the Egyptian National Hypertension Project (NHP). J Hum Hypertens 1997;11:709-726.

2 Central Agency for Public Mobilization and Statistics (CAPMAS): The annual health report of the year 1990. Cairo, CAPMAS, 1990.

-3 Abd Allah F, Baligh E, Ibrahim M: Clinical relevance of carotid atherosclerosis among Egyptians: a 5-year retrospective analysis of 4,733 subjects. Neuroepidemiology 2010;35:275-279.

-4 Bishara RA, Taha W, Alfarouk MO, Milik IA, Wilson N: Screening for significant carotid artery disease among a cohort of 1,000 Egyptian patients. Vascular 2008;16:35-40.

5 Lombardo A, Biasucci LM, Lanza GA, Coli S, Silvestri P, Cianflone D, et al: Inflammation as a possible link between coronary and carotid plaque instability. Circulation 2004;109:3158-3163.

- 6 Poulter NR, Khaw KT, Sever PS: Higher blood pressures of urban migrants from an African low-blood pressure population are not due to selective migration. Am J Hypertens 1988;1(pt 3):143S-145S.

7 Campos H, Mata L, Siles X, Vives M, Ordovas JM, Schaefer EJ: Prevalence of cardiovascular risk factors in rural and urban Costa Rica. Circulation 1992;85:648-658.

8 Heyman A, Fields WS, Keating RD: Joint study of extracranial arterial occlusion. 6. Racial differences in hospitalized patients with ischemic stroke. JAMA 1972;222:285-289.

-9 Caplan LR, Gorelick PB, Hier DB: Race, sex and occlusive cerebrovascular disease: a review. Stroke 1986;17:648-655.

10 Nguyen-Thanh HT, Benzaquen BS: Screening for subclinical coronary artery disease measuring carotid intima media thickness. Am J Cardiol 2009; 15; 104:1383-1388

11 Mancini GBJ, Dahlof B, Diez J: Surrogate markers for cardiovascular disease structural markers. Circulation 2004;109(suppl 4):22-30.

12 Greenland P, Abrams J, Aurigemma GP, Bond MG, Clark LT, Criqui $\mathrm{MH}$, Crouse JR 3rd, Friedman L, Fuster V, Herrington DM, Kuller LH, Ridker PM, Roberts WC, Stanford W, Stone N, Swan HJ, Taubert KA, Wexler L: Prevention Conference V - beyond secondary prevention: identifying the high-risk patient for primary prevention - noninvasive tests of atherosclerotic burden. Writing Group III. Circulation 2000; 101:E16-E22.

\section{KARGER}

Fax +41613061234 E-Mail karger@karger.ch www.karger.com
(C) 2010 S. Karger AG, Basel

0251-5350/10/0354-0280\$26.00/0

Accessible online at:

www.karger.com/ned
Dr. Nicola Cicorella

Department of Cardiovascular and Thoracic Disease

Carlo Poma Hospital, Via Lago Paiolo 1

IT-46100 Mantova (Italy)

Tel. +39 0376201 303, Fax +39 0376201 970, E-Mail cicorella.nicola @ libero.it 